\title{
Microbiologically influenced corrosion of orthodontic metallic appliances
}

\author{
Takashi KAMEDA ${ }^{1}$, Hirotake ODA², Kazuo OHKUMA ${ }^{3}$, Natsuki SANO'1, Nomintsetseg BATBAYAR ${ }^{1}$, \\ Yukari TERASHIMA ${ }^{1}$, Soh SATO ${ }^{2}$ and Kazuto TERADA ${ }^{1}$ \\ ${ }^{1}$ Department of Orthodontics, The Nippon Dental University, School of Life Dentistry at Niigata, 1-8 Hamaura-cho, Chuo-ku, Niigata City, Niigata \\ 951-8580, Japan \\ ${ }^{2}$ Department of Periodontology, The Nippon Dental University, School of Life Dentistry at Niigata, 1-8 Hamaura-cho, Chuo-ku, Niigata City, Niigata \\ 951-8580, Japan \\ ${ }^{3}$ Department of Dental Materials Science, The Nippon Dental University, School of Life Dentistry at Niigata, 1-8 Hamaura-cho, Chuo-ku, Niigata City, \\ Niigata 951-8580, Japan \\ Corresponding author, Takashi KAMEDA; E-mail: tkameda@ngt.ndu.ac.jp
}

\begin{abstract}
Biocorrosion (microbiologically influenced corrosion; MIC) occur in aquatic habitats varying in nutrient content, temperature, stress and $\mathrm{pH}$. The oral environment of organisms, including humans, should be one of the most hospitable for MIC. Corrosion of metallic appliances in the oral region is one cause of metal allergy in patients. In this study, an inductively coupled plasma-optical emission spectrometer revealed elution of $\mathrm{Fe}$, $\mathrm{Cr}$ and $\mathrm{Ni}$ from stainless steel (SUS) appliances incubated with oral bacteria. Three-dimensional laser confocal microscopy also revealed that oral bacterial culture promoted increased surface roughness and corrosion pits in SUS appliances. The $\mathrm{pH}$ of the supernatant was lowered after co-culture of appliances and oral bacteria in any combinations, but not reached at the level of depassivation $\mathrm{pH}$ of their metallic materials. This study showed that Streptococcus mutans and Streptococcus sanguinis which easily created biofilm on the surfaces of teeth and appliances, did corrode orthodontic SUS appliances.
\end{abstract}

Keywords: Oral bacteria, Metallic elution, Surface roughness, Stainless steel, Nickel titanium

\section{INTRODUCTION}

Physicochemical interactions between a metallic material and its environment can lead to corrosion. Electrochemical corrosion is a chemical reaction involving the transfer of electrons from a zero-valent metal to an external electron acceptor, causing the release of metal ions into the surrounding medium and deterioration of the metal ${ }^{1}$. Microbial activity within biofilms that form on the surface of metallic materials can affect the kinetics of cathodic and/or anodic reactions and can considerably modify the chemistry of any protective layers, leading to acceleration or inhibition of corrosion ${ }^{2-4)}$. Biofouling and biocorrosion (microbiologically influenced corrosion, MIC) occur in aquatic habitats varying in nutrient content, temperature, stress and $\mathrm{pH}^{11}$.

The oral environment of organisms including humans should be one of the most hospitable for biofilm creation and MIC. Many reports on MIC concern steel and stainless steel (SUS) material ${ }^{1}$. SUS materials have been widely used as appliances in orthodontic treatment. Corrosion of metallic appliances in the oral region, especially with the release of nickel, is one cause of metal allergy in patients ${ }^{5-8}$. SUS contains approximately 8-10 wt\% nickel for resistance against non-oxidation acid, such as sulfuric or hydrochloric acid. Nickel titanium (NiTi) materials possess mechanical superelasticity, so that NiTi material, which contains

Color figures can be viewed in the online issue, which is available at J-STAGE.

Received Oct 24, 2013: Accepted Dec 17, 2013

doi:10.4012/dmj.2013-297 JOI JST.JSTAGE/dmj/2013-297
$45-60 \mathrm{wt} \%$ nickel, is widely used in dental treatment, especially in orthodontic treatment. Prior reports of the electrochemical corrosion of dental materials including orthodontic wires by oral bacteria indicated that the corrosion current of $\mathrm{NiTi}$ wires was high compared with that of SUS wires ${ }^{9-11}$. Consequently, the corrosion resistance of titanium metal was relatively high. However, fluoride-containing environments degrade the protective surface oxide and reduce corrosion resistance ${ }^{12-14)}$.

This study showed that representative indigenous oral bacteria, Streptococcus mutans and Streptococcus sanguinis easily created biofilm on the surfaces of teeth and appliances and did corrode SUS but not NiTi orthodontic appliances. These findings were confirmed by measuring metallic elution with an inductively coupled plasma-optical emission spectrometer (ICPOES) and measuring surface roughness with threedimensional (3D) laser confocal microscopy.

\section{MATERIALS AND METHODS}

\section{Materials}

Orthodontic wires made of SUS (SUS304, Suzuki stainless wire, Mitsuba Ortho Supply Inc., Tokyo, Japan) and of NiTi (Sentalloy, Tomy International Inc., Tokyo, Japan) were prepared. The cross sectional size of the wires was approximately $0.43 \times 0.64 \mathrm{~mm}$ $(0.017 \times 0.025 \mathrm{in})$. Orthodontic SUS brackets (SUS304; SuperMeshBracket medium twin bondable for mandible incisors, Tomy International Inc., Tokyo, Japan) were 
also prepared. An SUS wire length of $3.0 \mathrm{~cm}$ was chosen, to have the same weight as the brackets ${ }^{15)}$. The NiTi wires were also prepared in the same lengths as SUS wires. Each orthodontic wire was tied to a bracket with elastomeric modules (polyurethane, elastic ligature tie, Shofu Inc., Tokyo, Japan). The immersion solution was Brain Heart Infusion medium (BHI; Beckton, Dickinson and Company Inc., Detroit, MI, USA) with or without indigenous oral bacteria $S$. mutans (ATCC49296) or S. sanguinis (ATCC25175).

\section{Culture of appliances with indigenous oral bacteria}

Appliances cultured with $S$. mutans or S. sanguinis in $3 \mathrm{~mL}$ of BHI medium in a $15 \mathrm{~mL}$ plastic tube and incubated at $37^{\circ} \mathrm{C}$ in $5 \% \mathrm{CO}_{2}$ in air without shaking. A saturated culture of $S$. mutans or $S$. sanguinis with an optical density (OD) of $0.6-1.0$ at $660 \mathrm{~nm}$ was diluted 40-fold with BHI medium (Difco Inc., Detroit, MI, USA) and incubated from day 0 to day 4 (Fig. 1). Cell growth was monitored by measuring the OD at $660 \mathrm{~nm}$ at $2,3,4.5,5.5,6.5,7.5,8.5,10$, and $24 \mathrm{~h}$ with or without each appliance, using a Mini Photo 518R (Taitec Inc., Tokyo, Japan) under 5\% $\mathrm{CO}_{2}$ conditions. Appliances were cultured with each species of oral bacteria for $3 \mathrm{~h}$ on day 0 and for $24 \mathrm{~h}$ on days $1-4$. Supernatants were collected at day 0-4, and appliances were collected at day 4 for evaluation of metallic elution and surface roughness, respectively (Fig. 1).

Supernatant $\mathrm{pH}$ after co-culture of orthodontic appliances with indigenous oral bacteria

Supernatants were centrifuged at $16,770 \times \mathrm{g}$ for $5 \mathrm{~min}$ to remove bacteria after co-culture with indigenous oral bacteria (Fig. 1). Supernatant pH was measured with a $\mathrm{pH}$ meter at day 0-4 (F-12, Horiba Inc., Kyoto, Japan). Mean $\mathrm{pH}$ values of the same tubes at day 0-4 were calculated, and evaluated mean \pm S.D. in each group. Before measurements were taken, the $\mathrm{pH}$ meter was calibrated using three standard solutions with $\mathrm{pH}$ of 4, 7 and 10 (MJ-PH4, MJ-PH7, MJ-PH10, Sato
Shouji Inc., Kanagawa, Japan).

Detection of metallic elution from orthodontic appliances cultured with indigenous oral bacteria using the ICPOES

ICP-OES measurements were acquired using Thermo Fisher Scientific ICP-OES model iCAP6300DUO, Waltham, MA, USA. Each BHI medium containing an appliance and indigenous oral bacteria was incubated at $37^{\circ} \mathrm{C}$ for $3 \mathrm{~h}$ on day 0 and for $24 \mathrm{~h}$ on days $1-4$. After incubation, each supernatant at day 0-4 from the same tubes was collected and combined without appliance or bacteria for the ICP-OES measurement (Fig. 1). The ICP-OES instrument was optimized before measurement using standard solutions of $\mathrm{Cr}, \mathrm{Fe}, \mathrm{Ni}$ and Ti for atomic absorption spectrometry (Kanto Chemical Co. Ltd., Tokyo, Japan), and operated according to the manufacturer's instructions. The ICP-OES spectrometer was used with the following parameters: FR power, $1.15 \mathrm{~kW}$; frequency, 27.12 $\mathrm{MHz}$; demountable quartz torch, Ar/Ar/Ar; plasma gas (Ar) flow, 16.5 $\mathrm{Lmin}^{-1}$; auxiliary gas (Ar) flow, $0.5 \mathrm{Lmin}^{-1}$; nebulizer gas (Ar) flow, $0.7 \mathrm{Lmin}^{-1}$; nebulizer pressure, 0.15 $\mathrm{MPa}$; glass spray chamber according to Scott (cyclone chamber, Fisher Scientific Inc., MA, USA); sample pump flow rate, $1.8 \mathrm{mLmin}^{-1}$; integration time, $45 \mathrm{~s}$; replicates, 5; and wavelength range of monochromator, 166-847 nm. Standard curves of BHI medium with or without $\mathrm{Cr}, \mathrm{Fe}, \mathrm{Ni}, \mathrm{Sn}$ and $\mathrm{Ti}$ were created, and then each detection limit (3.3\%/slope) and determination limit ( $10 \sqrt{ } 2 \delta /$ slope) were obtained according to ISO 118843 (Table 1). The elution values of metallic ions in the medium were shown as concentrations ( $\mathrm{ppb} / \mathrm{ppm})$, so that these values could be converted to the eluted metal weight / appliance $(\mu \mathrm{g})$ for easier understanding (Table 1). Selected metal ions were measured at wavelengths of $205.552 \mathrm{~nm}$ for $\mathrm{Cr}, 261.187 \mathrm{~nm}$ for $\mathrm{Fe}, 231.604 \mathrm{~nm}$ for $\mathrm{Ni}$ and $308.802 \mathrm{~nm}$ for Ti from the results of each standard curve (Table 1). Because the BHI medium contained bovine heart extract, which

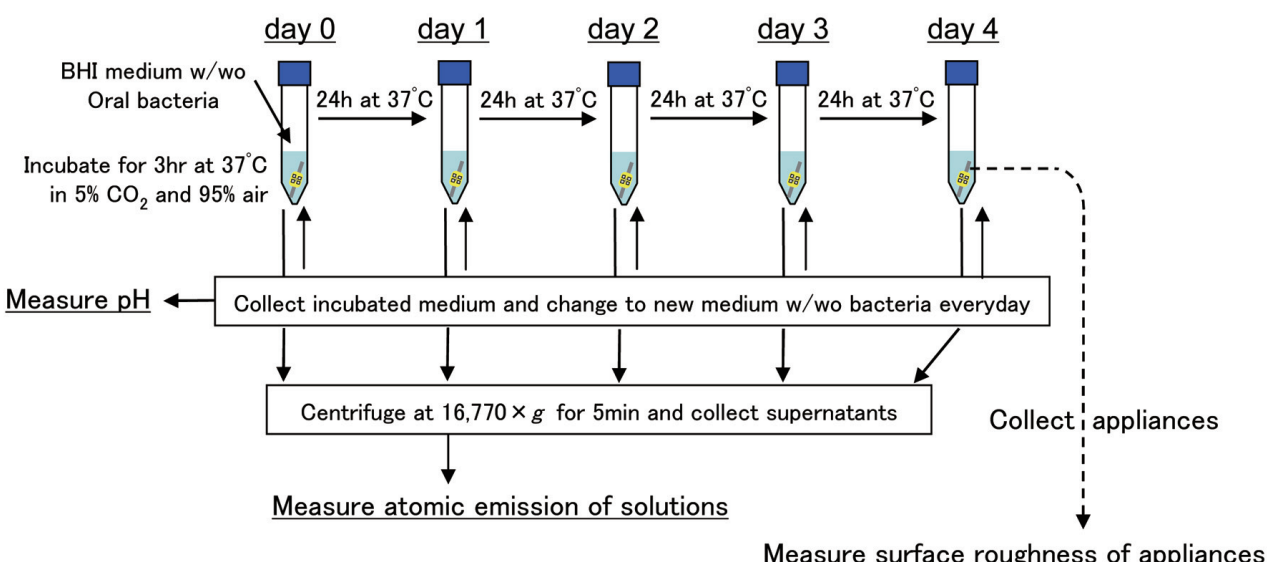

Fig. 1 Schematic representation and time schedules of experiment. 
should be an iron-rich tissue, the detection limit and determination limit of Fe were high compared with those of the other metallic elements (Table 1). The values of metallic elution were displayed as converted values $(\geq$ determination limit), + (detection values $\leq$ measured values $<$ determination limit) or - ( $<$ detection limit) (Table $2 \mathrm{a}-\mathrm{d}$ ). All reagents used were of analytical and spectral purity grade.

Table 1 ICP-OES detection and determination limits at different detection wavelengths for each element in BHI medium

\begin{tabular}{cccc}
\hline & Detection wavelength $(\mathrm{nm})$ & Detection limit $(\mu \mathrm{g})$ & Determination limit $(\mu \mathrm{g})$ \\
\hline $\mathrm{Cr}$ & 205.552 & 0.015 & 0.063 \\
$\mathrm{Fe}$ & 261.187 & 0.192 & 0.823 \\
$\mathrm{Ni}$ & 231.604 & 0.022 & 0.092 \\
$\mathrm{Ti}$ & 308.802 & 0.015 & 0.064 \\
\hline
\end{tabular}

Table 2 Elution amount of each element $(\mu \mathrm{g})$ from the appliances in supernatant a. Supernatant after culturing oral bacteria

\begin{tabular}{|c|c|c|}
\hline & S.mutans & S.sanguinis \\
\hline $\mathrm{Cr}$ & - & - \\
\hline $\mathrm{Fe}$ & - & - \\
\hline $\mathrm{Ni}$ & - & - \\
\hline $\mathrm{Ti}$ & - & - \\
\hline
\end{tabular}

b. Stainless steel wires with stainless steel brackets

\begin{tabular}{cccc}
\hline & Medium only & S.mutans & S.sanguinis \\
\hline $\mathrm{Cr}$ & - & + & + \\
$\mathrm{Fe}$ & - & $0.88 \pm 0.128$ & $1.83 \pm 0.250^{*}$ \\
$\mathrm{Ni}$ & - & + & + \\
\hline
\end{tabular}

c. Nickel titanium wires with stainless steel brackets

\begin{tabular}{cccc}
\hline & Medium only & S.mutans & S.sanguinis \\
\hline $\mathrm{Cr}$ & - & + & + \\
$\mathrm{Fe}$ & - & + & $0.92 \pm 0.231^{* *}$ \\
$\mathrm{Ni}$ & - & - & + \\
$\mathrm{Ti}$ & - & - & - \\
\hline
\end{tabular}

d. Stainless steel brackets with no wires

\begin{tabular}{cccc}
\hline & Medium only & S.mutans & S.sanguinis \\
\hline $\mathrm{Cr}$ & - & + & + \\
$\mathrm{Fe}$ & - & + & $0.93 \pm 0.120^{* *}$ \\
$\mathrm{Ni}$ & - & - & + \\
$\mathrm{Ti}$ & - & - & - \\
\hline
\end{tabular}

For each experimental condition, $n=6 .+$, detection values $\leq$ measured values $<$ determination limit), and - , measured values $<$ detection limit. The data were analyzed by Mann-Whitney U test to determine statistical significance. Superscript asterisks denote statistically significant differences $(p<0.05)$ between compared rows and between compared measurement elements for each immersion solution. *, S. mutans group; ${ }^{* *}$, stainless steel wire with stainless steel bracket; ${ }^{* * *}$, nickel titanium wire with stainless steel bracket. 
Detection of surface roughness of orthodontic appliances using the $3 D$ laser confocal microscope

The surface roughness of appliances was measured using a 3D laser measuring microscope (LEXT OLS4000, Olympus Inc., Tokyo, Japan) and estimated as $\mathrm{Ra}$ (the arithmetic average of the absolute value, $\mathrm{Ra}=\mathrm{n}^{-1} \sum|\mathrm{Yi}|(\mathrm{i}=1-\mathrm{n})$ ), $\mathrm{Rz}$ (the highest peaks (Rp) and lowest valleys $(\mathrm{Rv})$ over the entire sampling length, $\mathrm{Rz}=\mathrm{Rp}+\mathrm{Rv}$ ), and $\mathrm{Sa}$ (the arithmetic average of the $3 \mathrm{D}$ (areal) roughness) calculated by the Lext software

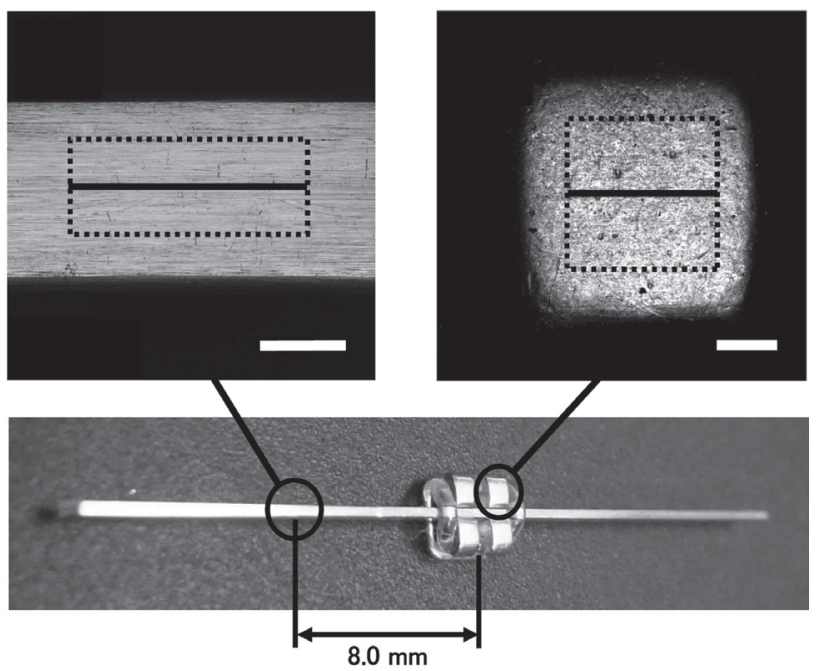

Fig. 2 Measurement area and lines of the brackets and wires for surface roughness measurement by 3D laser confocal microscopy.

Upper left: 3D laser confocal micrograph of stainless steel wire at a distance $8.0 \mathrm{~mm}$ from the center of the bracket; upper right: 3D laser confocal micrograph of wing of orthodontic bracket; lower: photo of orthodontic appliances (bracket $+3 \mathrm{~cm}$ of wire + elastomeric module) used in this study. White lines in the micrographs represent $100 \mu \mathrm{m}$. package (Olympus Inc.) on a workstation computer (MB-P5300X-WS, Mouse Computer Inc., Tokyo, Japan). Preparation of specimens for surface roughness estimation was performed as follows: 1) immersion medium with or without bacteria was discarded, 2) appliances were washed twice with distilled water (DW), 3) appliances were ultrasonicated twice in DW for $15 \mathrm{~min}$, 4) appliances were washed twice with DW, and 5) appliances were air-dried. Estimation of surface roughness was performed at a position $8 \mathrm{~mm}$ from the longitudinal central point on the labial surface of the wires (the $500 \mu \mathrm{m}$ mesiodistal line of the center of wires, over a $200 \times 500 \mu \mathrm{m}$ area of the wire surfaces), and the labial flat part of the wing surfaces of brackets (the $500 \mu \mathrm{m}$ mesiodistal line, over a $500 \times 500 \mu \mathrm{m}$ area of flat surfaces) (Fig. 2).

Experimental conditions, data and statistical analysis All experiments were performed in the laboratory, which was maintained at a temperature of $22 \pm 1^{\circ} \mathrm{C}$. Data were obtained from each experiment, and six results from a total of eight were used, with the maximum and minimum results discarded. The six results were calculated and represented as mean \pm standard deviation. The data were analyzed by Mann-Whitney U test to determine statistical significance.

\section{RESULTS}

Optical density changes of oral bacteria cultured with orthodontic appliances

Chronologic estimation of OD of each bacterial culture seeded with an initial OD of 0.01 with $S$. mutans and of 0.001 with $S$. sanguinis revealed significant elevation from $6 \mathrm{~h}$ in $S$. mutans and $2 \mathrm{~h}$ in $S$. sanguinis, and reached confluence at $8.5 \mathrm{~h}$ in $S$. mutans $(\mathrm{OD}=0.75-0.8)$ and at $6.5 \mathrm{~h}$ in $S$. sanguinis $(\mathrm{OD}=0.53-0.55)$, regardless of the presence of absence of appliances (Fig. 3). After reaching confluence, growth curves of $S$. mutans and $S$. sanguinis were exhibited stationary phases, and death
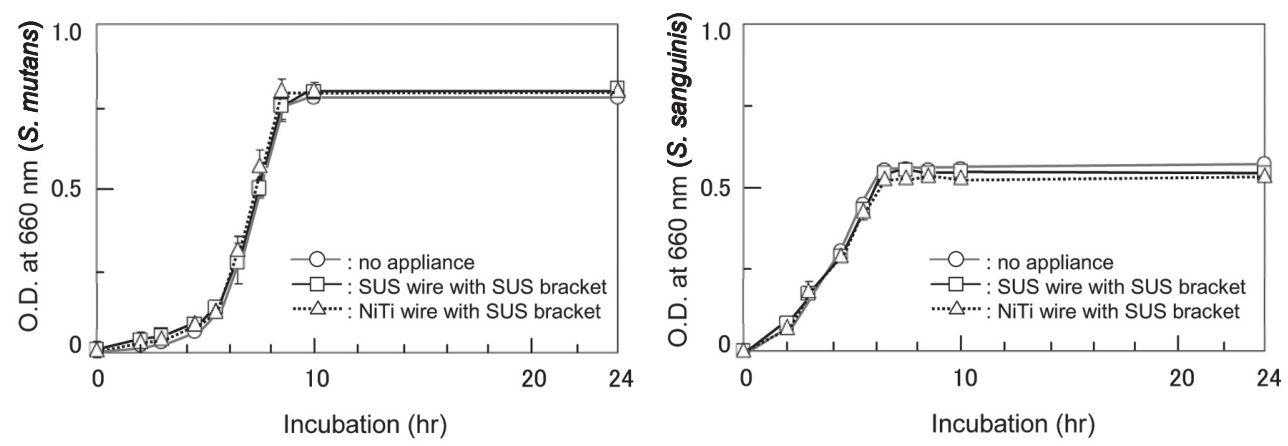

Fig. 3 Chronologic changes in optical density of oral bacteria incubated with orthodontic appliances. Left: optical density (OD) changes in S. mutans; right: OD changes in S. sanguinis. o with gray line represents the group incubated with oral bacteria without appliances in BHI medium; $\square$ with black line represents the group with bacteria with SUS wires + SUS brackets; $\triangle$ with black dotted line represents the group with bacteria with NiTi wires + SUS brackets. 
phases of them started at additional $72 \mathrm{~h}$ culture.

Changes in the pH of supernatant after culture of orthodontic appliances with oral bacteria

The $\mathrm{pH}$ of the medium was lowered by the culture of each bacterial species, each appliance, and each appliance with each bacterial species (Fig. 4). However, the lower $\mathrm{pH}$ could not have eroded these alloys directly, because no solution reached the depassivation $\mathrm{pH}^{18,19)}$. Differences in $\mathrm{pH}$ between supernatants with S. mutans and S. sanguinis in each culture condition (bacteria only, SUS brackets with SUS wires, and SUS brackets with NiTi wires) were not observed (Fig. 4).

Corrosion of stainless steel and titanium wires combined with stainless steel brackets after co-culture with oral bacteria

After vigorous DW washing of the appliances cultured with bacteria, deposits were still attached to the wire surfaces as observed with the 3D laser confocal microscope (Fig. 5). The deposits were convex to the wire surfaces as seen with surface scanning analysis by the laser microscope (Fig. 5). Because of this finding, the appliances co-cultured with bacteria were washed vigorously twice with $\mathrm{DW}$, ultrasonicated in DW twice for $15 \mathrm{~min}$, and washed again twice with DW. After these washing procedures, the wires showed no surface deposits under the laser microscope, and were used for the experiments.

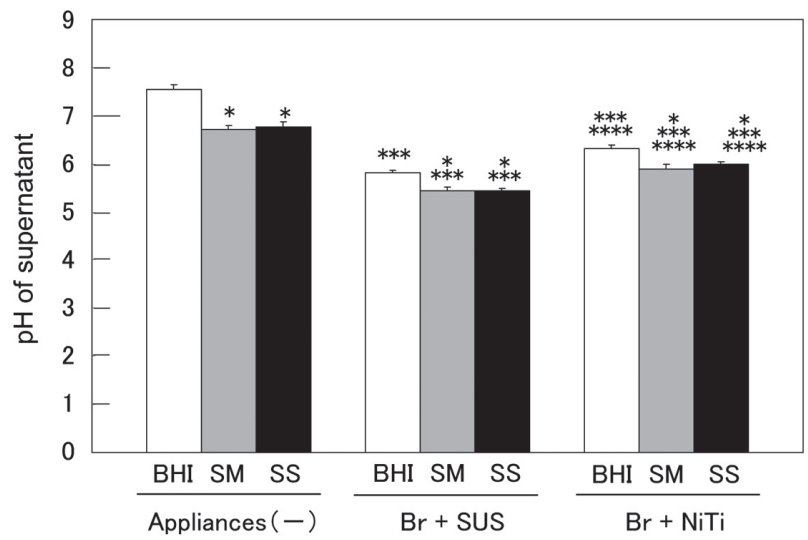

Fig. 4 Changes in $\mathrm{pH}$ of medium used to immerse the appliances with or without oral bacteria.

$n=6$ for each experimental condition. Br, bracket; SUS, stainless steel wire; NiTi, nickel titanium wire; BHI, brain heart infusion medium; SM, Streptococcus mutans; and SS, Streptococcus sanguinis. The data were analyzed by MannWhitney U test to determine statistical significance. Asterisks denote statistically significant differences $(p<0.05)$ between compared appliances and between compared immersion solutions. *, BHI; **, SM; ***, Appliances (-); ***, $\mathrm{Br}+\mathrm{SUS}$
Surface roughness of each wire was evaluated as $\mathrm{Ra}, \mathrm{Rz}$ and $\mathrm{Sa}$, calculated by the workstation based on surface scanning data from the laser microscope. Ra, $\mathrm{Rz}$ and $\mathrm{Sa}$ of each wire material combined with SUS brackets exhibited similar tendencies (Fig. 6). For SUS wires, surface roughness decreased in the following order: culture with $S$. sanguinis $>$ culture with $S$. mutans $>$ culture without bacteria $>$ intact product (Fig. 2).

Because the surfaces of intact appliances were not smooth and the amount of metallic elution from appliances was small (approximately 1/1000 the appliance weight; Table 2), obvious surface changes in the wires resulting from oral bacteria were difficult to detect. A slightly increased roughness, including corrosion pits, was seen with careful observation, supporting evaluation of surface roughness in terms of $\mathrm{Ra}, \mathrm{Rz}$ and $\mathrm{Sa}$ (Fig. 6). In the NiTi wires, there were no observed differences in surface roughness between intact wires and wires cultured with either species of oral bacteria (Fig. 6).

Metallic elution of each component of the wires to the medium was evaluated with the ICP-OES. Although the detection and determination limits of Fe were high compared with those of the other

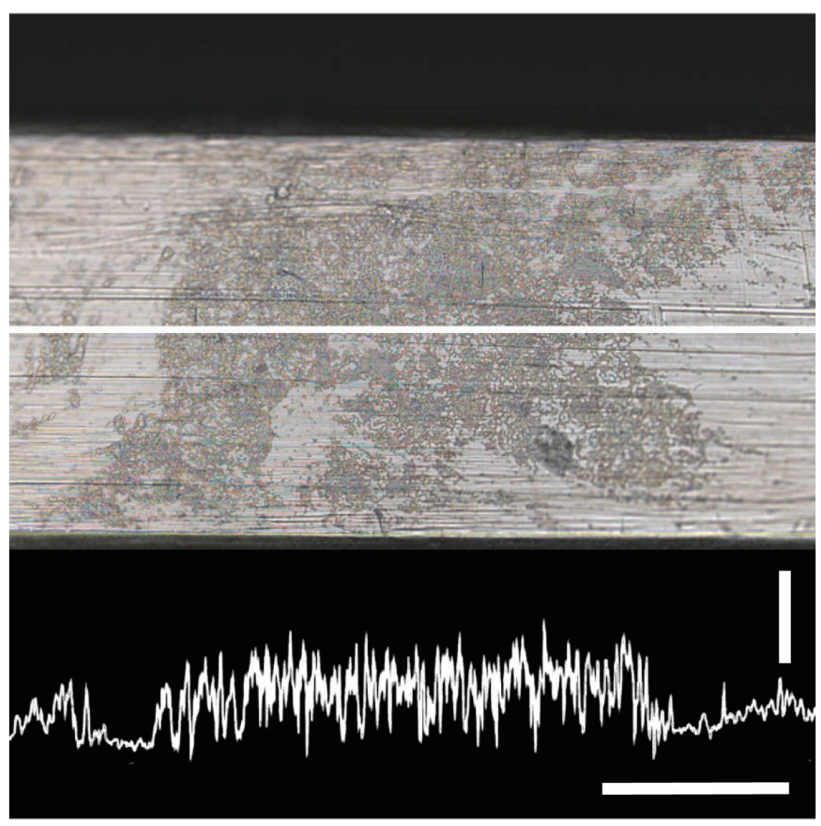

Fig. 5 Three-dimensional laser confocal micrograph and analysis of the surface roughness of an orthodontic stainless steel wire partly covered with $S$. mutans. The white horizontal line in the micrograph represents the surface roughness measurement area of the wires after vigorous washing with distilled water. The wire surface roughness results are shown as a white zigzag line under the wire. The thick white lines over and under the white zigzag line in the micrograph represent 50 and 100 $\mu \mathrm{m}$, respectively. 

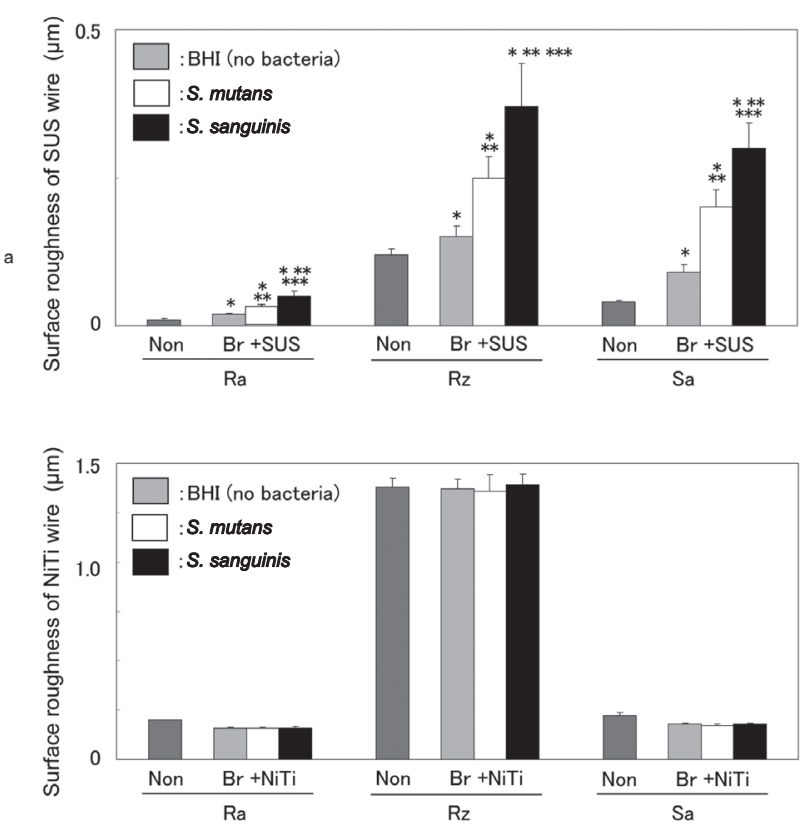

Fig. 6 Surface roughness of the SUS and NiTi wires cultured with oral bacteria in BHI medium.

For each experimental condition, $n=6$. Br, bracket; SUS, stainless steel wire; NiTi, nickel titanium wire; Non, non-immersed appliance (intact product); and BHI, brain heart infusion medium. Ra represents the arithmetic average of absolute value, $\mathrm{Rz}$ represents the highest peaks and lowest valleys over the entire sampling length, and Sa represents the arithmetic average of the $3 \mathrm{D}$ roughness (areal roughness). The data were analyzed by Mann-Whitney U test to determine statistical significance. Asterisks denote statistically significant differences $(p<0.05)$ between appliance types for each measurement item compared. *, Non; **, BHI; ***, S. mutans solution.

components, only Fe elution was detected as measured values ( $\geq$ determination limit) in each combination (Table 2). Cr and Ni elution were also detected, but at levels lower than the determination limits. No elution of Ti was observed. Elution of Fe from NiTi wires with SUS brackets cultured with $S$. sanguinis was almost equivalent to elution from SUS brackets without wires cultured with $S$. sanguinis (Table 2).

Corrosion of stainless steel brackets with or without stainless steel or nickel titanium wires after co-culture with oral bacteria

Surface roughness of SUS brackets in each combination was evaluated as $\mathrm{Ra}, \mathrm{Rz}$ and $\mathrm{Sa}$, and similar tendencies were found in each combination (Fig. 7). The rank order of surface roughness of SUS brackets was: culture with $S$. sanguinis $>$ culture with $S$. mutans $>$ culture without bacteria $>$ intact product (Fig. 7). These were

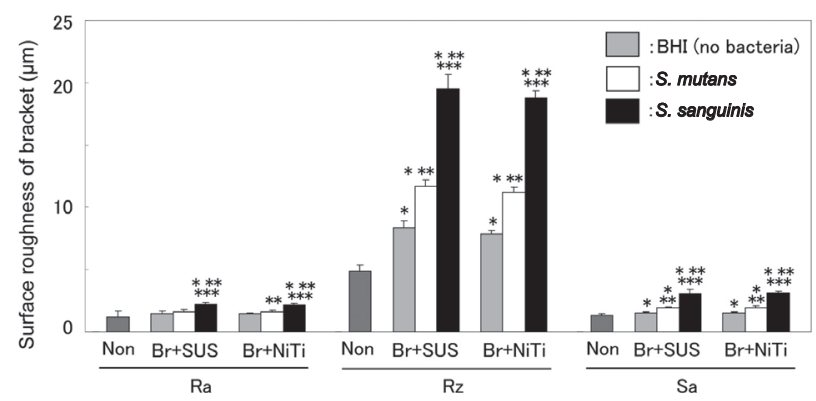

Fig. 7 Surface roughness of the SUS brackets combined with SUS wires or NiTi wires cultured with oral bacteria in BHI medium.

For each experimental condition, $n=6$. Br, bracket; SUS, stainless steel wire; NiTi, nickel titanium wire; Non, non-immersed appliance (intact product); and BHI, brain heart infusion medium. Ra represents the arithmetic average of absolute value, $\mathrm{Rz}$ represents the highest peaks and lowest valleys over the entire sampling length, and Sa represents the arithmetic average of the 3D roughness (areal roughness). The data were analyzed by MannWhitney U test to determine statistical significance. Asterisks denote statistically significant differences $(p<0.05)$ between appliances for each measurement item compared. *, Non; **, BHI; ***, S. mutans solution.

the same trends found in the SUS wire experiments.

The surfaces of intact appliances were not smooth and the amount of metallic elution from appliances was small (approximately 1/1000 appliance weight; Table 2). However, obvious surface changes in the SUS brackets caused by $S$. sanguinis and $S$. mutans were observed as numerous corrosion pits, supporting evaluation of surface roughness as $\mathrm{Ra}, \mathrm{Rz}$ and $\mathrm{Sa}$ (Fig. 6). These bracket surface changes did not depend on the type of wire attached to brackets. These results suggest that corrosion of orthodontic appliances by oral bacteria rather than by galvanic current occurs mainly in SUS materials. Bracket surface roughness corresponded with metallic elution (Table 2). The elution of each metallic component from brackets to medium was evaluated from the data using SUS brackets with no wires. Fe, $\mathrm{Cr}$ and Ni elution were detected. No Ti elution was observed when SUS brackets were combined with NiTi wires. Based on the elution of Fe from SUS brackets without wire cultured with $S$. sanguinis, $\mathrm{Ni}$ elution from SUS brackets with NiTi wires likely derived from the SUS brackets.

\section{DISCUSSION}

Intraoral aging of orthodontic materials includes plasticization of polymeric adhesives and increased porosity and roughness of metallic alloys, which disturb smooth treatment progress and cause loss of time and 
A. Stainless steel wires
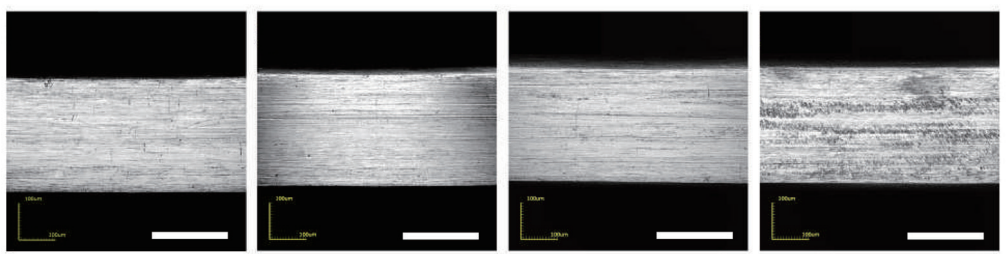

B. Nickel titanium wires
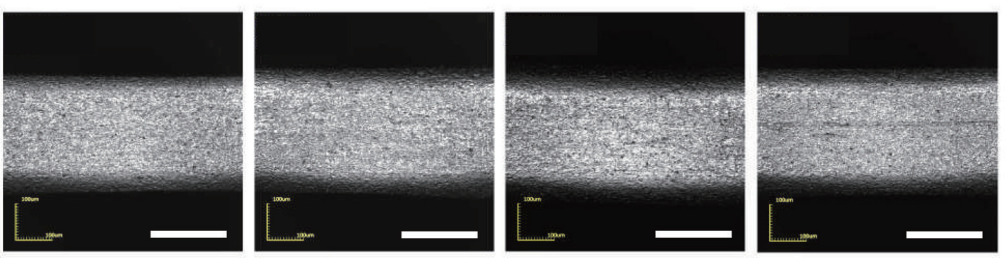

C. Stainless steel braket without wires
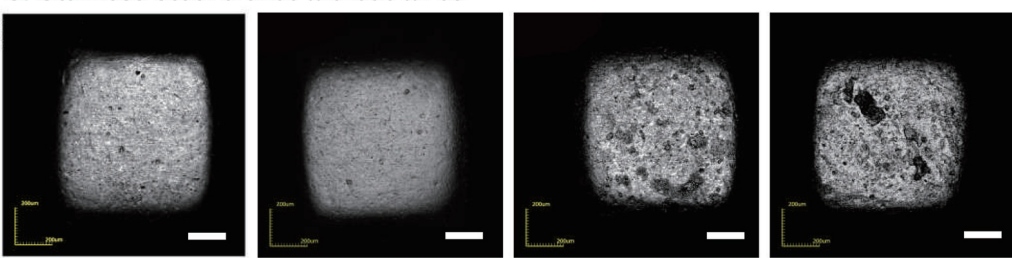

D. Stainles steel brackets with stainless steel wires
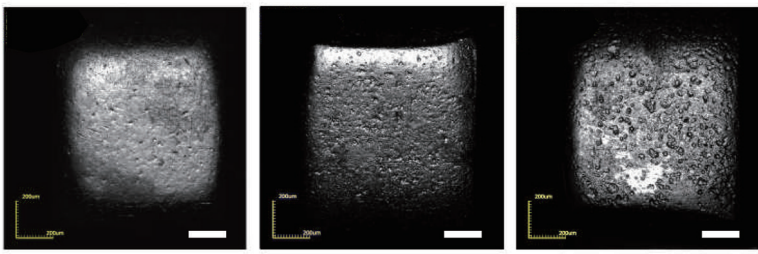

E. Stainless steel brackets with nickel titanium wires
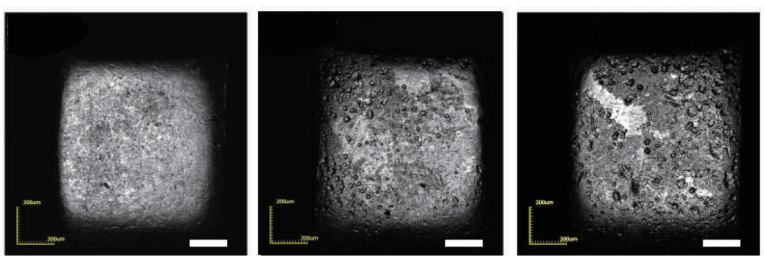

Cultured with (-)

$(-)$

S. mutans

S. sanguinis

No medium

BHI medium

Fig. 8 Three-dimensional laser confocal micrographs of the wire surfaces $(\times 20)$ and the brackets $(\times 10)$ cultured with oral bacteria in BHI medium.

White line represents $200 \mu \mathrm{m}$.

money as well as emotional distress for patients and clinicians ${ }^{16,17)}$. Although the electrochemical behaviors of orthodontic wires in the presence of oral bacteria have been reported ${ }^{9,11)}$, actual corrosion values supported by metallic elution studies and surface changes of appliances by micrographs could not be found. Compared with SUS, titanium alloys show excellent corrosion resistance because they have a highly protective $\mathrm{TiO}_{2}$ oxide surface film. Titanium alloys also have strong resistance to corrosion by electric current $^{9,11)}$. In this study, microbiologically influenced corrosion (MIC) of dental alloys by oral bacteria was found in SUS materials but not in titanium materials.

Biofilm creation and MIC (biocorrosion) occur in aquatic habitats varying in nutrient content, temperature, stress and $\mathrm{pH}^{11}$. From the results of chronologic estimation of OD of each bacterial culture, orthodontic SUS and NiTi appliances themselves have 
no effects, including toxic effects, on the proliferation of oral bacteria (Fig. 1). However, the $\mathrm{pH}$ of the medium was lowered by the culture of each bacterial species, each appliance, and each appliance with each bacterial species (Fig. 1). This lower $\mathrm{pH}$ could not have eroded these alloys directly, because no solution reached the depassivation $\mathrm{pH}^{18,19)}$. However, these $\mathrm{pH}$ results in supernatants should not always reflect local $\mathrm{pH}$ changes between bacteria/biofilm and appliance surfaces. Besides local $\mathrm{pH}$ changes, local cathode-anode reaction at contact surfaces of metal and bacteria was reported to be one of the causes of $\mathrm{MIC}^{1}$. Furthermore detailed information could be needed about local $\mathrm{pH}$ and electric changes in the future.

Surface roughness of each wire was evaluated as $\mathrm{Ra}, \mathrm{Rz}$ and Sa using the laser microscope. $\mathrm{Ra}, \mathrm{Rz}$ and $\mathrm{Sa}$ of each wire material combined with SUS brackets exhibited similar tendencies (Fig. 2). For SUS wires, surface roughness decreased in the following order: culture with $S$. sanguinis $>$ culture with $S$. mutans $>$ culture without bacteria > intact product (Fig. 2 ). Because the surfaces of intact appliances were not smooth, a slightly increased surface roughness, including corrosion pits in SUS wires was seen with careful observation, supporting evaluation of surface roughness in terms of $\mathrm{Ra}, \mathrm{Rz}$ and $\mathrm{Sa}$ (Fig. 3). In contrast to SUS wires, there were no observed differences in surface roughness between intact wires and wires cultured with either species of oral bacteria in the NiTi wires (Figs. 2, 3). These results support previous reports of the high resistance of titanium alloys to corrosion ${ }^{9,11}$. In contrast to the wires, obvious surface changes in the SUS brackets caused by S. sanguinis and S. mutans were observed as numerous corrosion pits, supporting evaluation of surface roughness as $\mathrm{Ra}, \mathrm{Rz}$ and $\mathrm{Sa}$ (Fig. 3). Bracket surface roughness also corresponded with metallic elution (Table 1). These bracket surface changes did not depend on the type of wire attached to brackets. Corrosion pits caused by $S$. mutans and S. sanguinis were clearly observed on SUS brackets, though these were not clearly seen on SUS wire surfaces. Corrosion probably depends on the surface quality of intact products caused by their processes of manufacture, i.e. brackets in this study produced by casts, and wires by wire drawing. These results also suggest that corrosion of orthodontic appliances by oral bacteria rather than by galvanic current occurs mainly in SUS materials.

Metallic elution of each component of the wires to the medium was evaluated with the ICP-OES. Although the detection and determination limits of $\mathrm{Fe}$ were high compared with those of the other components, only $\mathrm{Fe}$ elution was detected as measured values $(\geq$ determination limit) in each combination (Table 2). $\mathrm{Cr}$ and $\mathrm{Ni}$ elution were also detected, but at levels lower than the determination limits. No elution of Ti was detected. The elution of each metallic component from brackets to medium was evaluated from the data using SUS brackets with no wires. $\mathrm{Fe}, \mathrm{Cr}$ and $\mathrm{Ni}$ elution were detected. No Ti elution was detected when SUS brackets were combined with NiTi wires. Based on the elution of Fe from SUS brackets without wire cultured with S. sanguinis, Ni elution from SUS brackets with NiTi wires likely derived from the SUS brackets. These results suggest that corrosion of orthodontic appliances by the oral bacteria $S$. mutans and $S$. sanguinis affects mainly SUS materials.

In this study, we show that representative indigenous oral bacteria $S$. mutans and S. sanguinis which easily create biofilm on the surfaces of teeth and appliances, corroded SUS orthodontic appliances when cultured with them. Corrosion of metallic appliances in the oral region by oral bacteria releases metal ions such as nickel, and may be one cause of metallic allergy in patients, and further studies are needed concerning this point.

\section{CONCLUSIONS}

The oral environment of humans should be one of the most hospitable for biofilm creation and biofouling. The ICP-OES revealed the elution of $\mathrm{Fe}, \mathrm{Cr}$ and $\mathrm{Ni}$ from orthodontic SUS appliances but not from NiTi appliances, when cultured with indigenous oral bacteria. Three-dimensional laser confocal microscopy also revealed increased surface roughness and corrosion pits in SUS appliances co-cultured with oral bacteria. While bacterial culture influenced corrosion of orthodontic metal appliances, the appliances had no effect on the proliferation of oral bacteria. The $\mathrm{pH}$ of the supernatant was lowered after co-culture of appliances with oral bacteria in any combination, however, the $\mathrm{pH}$ did not decrease below the depassivation level of the alloys; therefore, the appliances did not erode. Representative indigenous oral bacteria $S$. mutans and $S$. sanguinis easily created biofilm on the surfaces of teeth and appliances, and corroded SUS but not NiTi orthodontic appliances when cultured with them.

Corrosion of metallic appliances in the oral region by oral bacteria releases metal ions such as nickel, and may be one cause of metallic allergy in patients.

\section{REFERENCES}

1) Beech IB, Sunner J. Biocorrosion: towards understanding interactions between biofilms and metals. Curr Opin Biotechnol 2004; 15: 181-186.

2) Jones DA, Amy PS. A themodynamic interpretation of microbiologically influenced corrosion. Corrosion 2002; 58: 638-645.

3) Little B, Ray R. A perspective on corrosion inhibition by biofilms. Corrosion 2002; 58: 424-428.

4) Ornek D, Wood TK, Hsu CH, Sun Z, Mansfeld F. Pitting corrosion control of aluminium 2024 using protective biofilms that secrete corrosion inhibitors. Corrosion 2002; 58: 761767.

5) Jensen CS, Lisby S, Baadsgaard O, Byrialsen K, Menné T. Release of nickel ions from stainless steel alloys used in dental braces and their patch test reactivity in nickelsensitive individuals. Contact Dermatitis 2003; 48: 300-304.

6) Menezes LM, Campos LC, Quintão CC, Bolognese AM. Hypersensitivity to metals in orthodontics. Am J Orthod 
Dentofacial Orthop 2004; 126: 58-64.

7) Noble J, Ahing SI, Karaiskos NE, Wiltshire WA. Nickel allergy and orthodontics, a review and report of two cases. Br Dent J 2008; 204: 297-300.

8) Kolokitha OE, Chatzistavrou E. Allergic reactions to nickel-containing orthodontic appliances: clinical signs and treatment alternatives. World J Orthod 2008; 9: 399-406.

9) Bahije L, Benyahia H, El Hamzaoui S, Ebn Touhami M, Bengueddour R, Rerhrhaye W, Abdallaoui F, Zaoui F. Behavior of NiTi in the presence of oral bacteria: Corrosion by Streptococcus mutans. Int Orthod 2011; 9: 110-119.

10) Chang JC, Oshida Y, Gregory RL, Andres CJ, Barco TM, Brown DT. Electrochemical study on microbiology-related corrosion of metallic dental materials. Biomed Mater Eng 2003; 13: 281-295.

11) Maruthamuthu S, Rajasekar A, Sathiyanarayanan S, Muthukumar N, Palaniswamy N. Electrochemical behaviour of microbes on orthodontic wires. Curr Sci 2005; 89: 988-996.

12) Lausmaa J, Kasemo B, Hansson S. Accelerated oxide growth on titanium implants during autoclaving caused by fluorine contamination. Biomaterials 1985; 6: 23-27.

13) Matono $Y$, Nakagawa M, Matsuya S, Ishikawa K. Corrosion behavior of pure titanium and titanium alloys in various concentration of acidulated phosphate fluoride (APF) solutions. Dent Mater J 2006; 25: 104-112.

14) Nakagawa M, Matsuya S, Shiraishi T, Ohta M. Effect of fluoride concentration and $\mathrm{pH}$ on corrosion of titanium for dental use. J Dent Res 1999; 78: 1568-1572.

15) Kameda $T$, Ohkuma $K$, Oda $H$, Sano $N$, Batbayar $N$, Terashima Y, Sato S, Terada K, Magnetic fields from electric toothbrushes promote corrosion in orthodontic stainless steel appliances but not in titanium appliances. Dent Mater J 2013; 32: 959-969.

16) Eliades T, Athanasios AE. In vivo aging of orthodontic alloys: Implications for corrosion potential, nickel release, and biocompatibility. Angle Orthod 2002; 72: 222-237.

17) Eliades T, Bourauel C. Intraoral aging of orthodontic materials: the picture we miss and its clinical relevance. Am J Orthod Dentfacial Orthop 2005; 127: 403-412.

18) Nash B, Kelly R. Characterization of the crevice solution chemistry of 304 stainless steel. Corros Sci 1993; 35: 817. 825.

19) Schiff N, Gosgpgeat B, Lissac M, Dalard F. Influence of fluoride content and $\mathrm{pH}$ on the corrosion resistance of titanium and its alloys. Biomaterials 2002; 23: 1995-2002. 